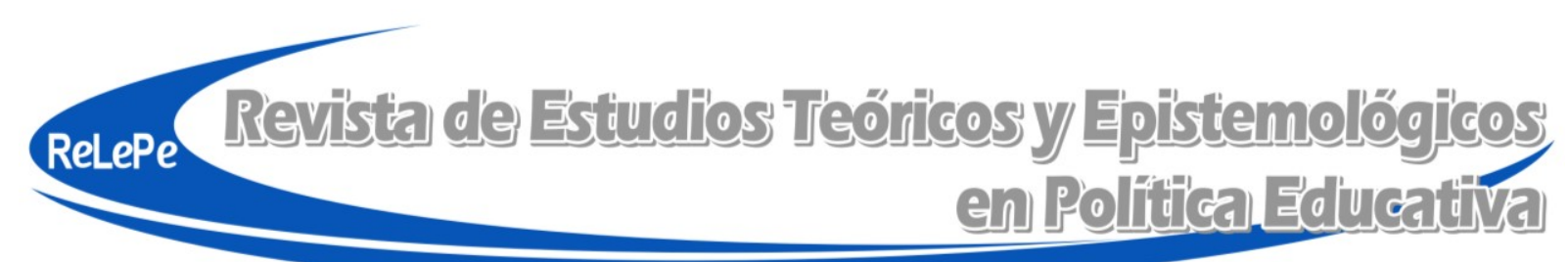

ISSN 2409-3696

DOI: $10.5212 /$ retepe.v.2.017

\title{
A disciplina de Política Educacional nos cursos de Pedagogia: um estudo preliminar
}

\author{
Gislaine Macedo Marçal Perão \\ Universidade Estadual do Centro-Oeste, Brasil \\ gislainemacedopedagogia@gmail.com \\ Michelle Fernandes Lima \\ Universidade Estadual do Centro-Oeste, Brasil \\ mfernandeslima@yahoo.com.br
}

\begin{abstract}
Resumo: O artigo apresenta os resultados de uma pesquisa que teve como tema central a disciplina de Política Educacional nos cursos de Pedagogia, realizada no âmbito do curso de Pedagogia UNICENTRO (PR). O objetivo foi identificar a nomenclatura, carga horária e ano de oferta da disciplina de Política Educacional em três cursos de Pedagogia de Universidades Estaduais do Paraná, bem como os principais desafios encontrados pelos professores em relação a esse campo de estudo. O levantamento e a análise de dados ocorreram por meio de pesquisas dos projetos pedagógicos de cursos nos sites dos institucionais, e questionário via e-mail aos professores que atuam na disciplina de Política Educacional no curso de Pedagogia das três instituições pesquisadas. A partir da pesquisa realizada podemos observar que a disciplina de Política Educacional é de suma importância na formação de professores, ocupa um espaço obrigatório nos cursos de licenciatura, e contempla questões econômicas, políticas, históricas e sociais da educação.
\end{abstract}

Palavras-chave: Políticas Educacionais. Disciplina de Política Educacional. Curso de Pedagogia. Projeto Pedagógico de Curso. Pesquisa em Política Educacional.

\section{The subject Education Policy in pedagogy courses: a preliminary study}

\begin{abstract}
The article presents the results of a research that has as its central theme the subject Educational Policy in the Pedagogy courses, performed within the scope of the UNICENTRO (PR) Pedagogy course. The objective was to identify the nomenclature, time and year of offer the subject Educational Policy in three Pedagogy courses of State University of Paraná, as well as the main challenges encountered by teachers regarding to this field of study. Data collection and analysis were carried out through researches of the pedagogical projects of courses in the institutional websites and questionnaire emailed to the teachers who work with the subject Educational Policy in the Pedagogy courses of the three institutions surveyed. From the research performed, we can observe the subject Educational Policy is paramount for teachers formation, occupies a mandatory space in undergraduate courses and contemplates economic, political, historical and social Education issues.
\end{abstract}

Keywords: Educational Policies. Subject Educational Policy. Pedagogy Course. Course Pedagogical Project. Research in Educational Policy. 


\section{La asignatura de política educacional en los cursos de pedagogía: un estudio preliminar}

Resumen: El artículo presenta los resultados de una investigación que tiene como tema central la asignatura de Política Educativa en los cursos de Pedagogía, realizada en el ámbito del curso de Pedagogía UNICENTRO (PR). El objetivo fue identificar la nomenclatura, carga horaria y año de oferta de la signatura de Política Educativa en tres cursos de Pedagogía de Universidades Estaduales de Paraná, así como los principales desafíos encontrados por los profesores en relación a ese campo de estudio. El relevamiento y análisis de datos ocurrió por medio de investigaciones de los proyectos pedagógicos de cursos en los sitios de las instituciones y cuestionario vía e-mail a los profesores que se desempeñan en la signatura de Política Educativa en el curso de Pedagogía de las tres instituciones encuestadas. Desde la investigación realizada se puede observar que la asignatura de Política Educativa es de suma importancia en la formación de profesores, ocupa un espacio obligatorio en los cursos de licenciatura y contempla cuestiones económicas, políticas, históricas y sociales de la educación.

Palabras clave: Políticas Educativas. Asignatura de Política Educativa. Curso de Pedagogía. Proyecto Pedagógico de Curso. Investigación en Política Educativa

\section{Introdução}

A disciplina de Política Educacional contempla o estudo das leis referentes à educação, autores que auxiliam na compreensão da realidade educacional, entre outros aspectos. A partir da década de 1990, a disciplina passou a ser incluída nos cursos de Pedagogia e Licenciaturas, tendo diversas denominações (Mainardes, Stremel \& Rosa, 2017), como será apresentado a seguir.

O objetivo da pesquisa foi investigar como a disciplina é ofertada em três Instituições Estaduais de Ensino Superior do estado do Paraná, identificando o ano de oferta, carga horária, ementa e programa; além disso, informações junto aos professores que ofertam a disciplina de Política Educacional nos cursos de Pedagogia em relação aos principais desafios enquanto docentes desse campo de estudo.

A justificativa para realização desta pesquisa ocorreu pela necessidade de verificar como a disciplina é apresentada em outros cursos de Pedagogia, visto que os conteúdos são de suma importância para a compreensão do sistema educativo e, consequentemente, para a formação de professores. Também para oferecer algumas contribuições para possíveis reformulações no projeto pedagógico do curso de Pedagogia.

Para investigar esta problemática, percorremos um determinado caminho: no primeiro momento realizamos um estudo sobre os conceitos de Disciplina, Política Educacional, Estado e Campo. Após, realizamos um levantamento de pesquisas relacionadas à disciplina de Política Educacional, tendo como autores Stremel \& Mainardes (2015), Flach \& Masson (2014), Costa, Muranaka \& Borghi (2015), Mainardes, Stremel \& Rosa (2017), Pronko (2016), Mainardes \& Stremel (2017); Mendes (2015), Moreira \& Iulianelli (2017), Rosa (2016), Mancebo (2017) e Giovine (2016), Guimarães-Iosif, Limeira \& Santos (2018). Além destes autores, foram consultados outros documentos, como ementas e programas nos sites das instituições.

No segundo momento, como forma de complementar as informações, realizamos um questionário via e-mail com professores que ministram a disciplina de Política Educacional nas instituições pesquisadas, com o intuito de conhecer sua posição em relação a essa disciplina.

\section{A disciplina de Políticas Educacionais: apontamentos iniciais}

Segundo Chervel (1990 apud Junior; Galvão, 2005), o termo disciplina como conteúdos de ensino passou a ser usado nas primeiras décadas do século XX, antes disso, até o século XIX, era 
usada para manter a ordem dos estabelecimentos e dos alunos, e ligada ao exercício intelectual. Portanto, os termos usados naquele período em relação aos conteúdos de ensino foram: partes, objetos, ramos, ou matérias de ensino.

Foi após a $1^{\text {a }}$ Guerra Mundial que o termo disciplina caracterizou-se como as matérias de ensino, relacionado com os conteúdos, mas não perdendo a função de exercitar o intelecto, pois era acompanhada de métodos e regras.

De acordo com o verbete de Oliveira (2010), citando alguns autores, podemos compreender o conceito de politica educacional. Van Zanten (2008) define as políticas educacionais como programas ligados à ação governamental, direcionadas ao público escolar e implementadas pela administração escolar e os profissionais da escola, ou seja, podemos compreendê-las interligadas ao Estado. Outro autor citado por Oliveira (2010), Paviglianiti (1993) compreende a política educacional como um estudo das relações de força, que busca direção para o processo educacional e as disputas que ocorrem no interior do Estado.

O Estado, segundo Gramsci e citado por Sheen (2007), é formado pela sociedade civil e pela sociedade política. A sociedade civil é formada pelo conjunto das organizações que têm como tarefa a elaboração e difusão de determinadas ideologias; alguns exemplos são: escolas, igrejas, sindicatos, etc. A sociedade política é composta pelos mecanismos que a classe dominante utiliza para manter o poder e sua hegemonia. Estes mecanismos podem ser os sistemas judiciários e a polícia militar, que agem por meio da lei e da força para alcançar os objetivos dessa sociedade.

De acordo com Sheen (2007), a política educacional constitui-se em dois momentos: o processo e o produto. [...] "Há, assim, dois momentos na Política Educacional: o momento do processo, de elaboração da tendência hegemônica, e o momento do produto, da materialização da política." [...] (SHEEN, 2007, p. 9). O processo caracteriza-se pelo ato da lei sendo elaborada e discutida pela sociedade civil, que não é uma sociedade harmônica e, portanto, possui diferentes posições a partir de determinados projetos sociais.

De acordo com Stremel (2016, 2017) e Stremel e Mainardes (2016), o campo acadêmico da política educacional surgiu, no Brasil, ao final da década de 1960, a partir de publicações de estudos sobre política educacional traduzidos e apresentados por autores brasileiros.

Durante aqueles anos foram criados espaços institucionais, tais como a Associação Nacional de Política e Administração da Educação - ANPAE, em 1961; o GT Estado e Política Educacional por meio da Associação Nacional de Pós-Graduação e Pesquisa em Educação ANPEd, em 1987; assim como a criação de disciplinas de Política Educacional nos cursos de graduação e pós-graduação, entre várias outras categorias, como revistas, pesquisas, eventos, etc.

Flach e Masson (2014) complementam que, a partir dos anos de 1990, com o neoliberalismo, o campo da política educacional começa a se desenvolver de forma distinta, com vários interlocutores, os quais defendiam as ações neoliberais, fortalecendo o capitalismo versus as propostas de transformações sociais em prol da classe trabalhadora.

Costa, Muranaka e Borghi (2015) apresentam a trajetória da disciplina de Política Educacional. Tudo começou com o Estatuto das Universidades Brasileiras, instituído pelo Decreto n 19.851 de 1931, nesse documento exigia-se, a todas as universidades, a composição de três institutos: Faculdade de Direito, Faculdade de Medicina, Escola de Engenharia e Faculdades de Filosofia, Ciências e Letras.

Em 1939, por meio do Decreto-Lei n ${ }^{\circ} 1.190$, a Faculdade Nacional de Filosofia da Universidade do Brasil ganha uma organização e, com isso, as "Faculdades de Filosofia, Ciências 
e Letras passaram a adotar na estruturação dos cursos de licenciatura e Pedagogia o chamado esquema 3 + 1" (Costa, Muranaka \& Borghi, 2015, p. 3).

Nesse modelo, ao término de três anos de estudo das disciplinas específicas, o egresso recebia o título de bacharel, e dos licenciados exigia-se mais um ano do curso de Didática, composto de Didática Geral, Didática Especial, Psicologia Educacional, Fundamentos Biológicos da Educação, Fundamentos Sociológicos da Educação e Administração Escolar (Costa; Muranaka; Borghi, 2015, p. 3).

Foi a partir de então que a disciplina ganhou sua primeira denominação: Administração Escolar. Esta denominação foi usada até 1962, quando foi substituída por "Estrutura e Funcionamento do Ensino, por meio do Parecer CFE 672/69, que fixou o conteúdo e a duração das licenciaturas, e do Parecer CFE 252/69, que disciplinou o curso de Pedagogia" (Costa; Muranaka; Borghi, 2015, p. 4).

Segundo Costa, Muranaka e Borghi (2015), nos dias atuais, a disciplina de Política Educacional ocupa um espaço obrigatório nos cursos de licenciatura, contemplando questões econômicas, políticas, históricas e sociais da educação, e tem como finalidade politizar os alunos. Esta formação sugere que o aluno obtenha uma visão contextualizada da realidade, e compreenda as relações entre a escola e a sociedade. As autoras concluem, em sua pesquisa, que a disciplina de Política Educacional Brasileira (PEB) auxilia o aluno a compreender como são organizadas as políticas públicas para a Educação, e que ela deve ser proposta segundo os parâmetros científicos relacionados com a realidade e direcionados à população, e não ser realizadas tendo em vista interesses privados de pequenos grupos.

De acordo com Flach e Masson (2014), no Brasil, o ensino de Política Educacional na formação de professores ocorreu durante o período tecnicista, por meio do Parecer no 252/69 (Brasil, 1969), que fixou a duração do currículo mínimo do curso de Pedagogia. A disciplina de Estrutura e Funcionamento do Ensino esteve presente nos currículos dos cursos de formação de pedagogos; mais tarde, também nos currículos das Licenciaturas.

Flach e Masson (2014) também abordaram, em sua pesquisa, a disciplina de Política Educacional e como ela ocorre em uma determinada universidade paranaense. As autoras chegaram à conclusão de que a disciplina possui seus conteúdos fragmentados, e os professores que a ministram, por vezes, não apresentam ligação direta com a área de Política Educacional, e frequentemente são desligados da universidade devido ao fim de contratos de trabalho.

Atualmente podemos perceber que a disciplina de Política Educacional possui várias nomenclaturas. No entanto, os conteúdos a serem trabalhados são similares. $\mathrm{Na}$ análise realizada pelos autores Stremel e Mainardes (2015), que pesquisaram 128 disciplinas de 70 universidades públicas, há 97 designações para a disciplina de Política Educacional. Porém, os termos mais usados são: Política Educacional, Políticas Educacionais e Política e gestão da educação. Eles também concluíram que, na maioria dos cursos de Pedagogia, a disciplina é ofertada nos dois primeiros anos, com carga horária de 60 horas, na maior parte dos currículos analisados.

Ainda segundo os mesmos autores:

Os tópicos mais presentes nas ementas são os seguintes:

a) Aspectos relacionados à organização da educação brasileira

(sistema educacional brasileiro, níveis, modalidades);

b) Aspectos da legislação educacional (Constituições Federais, leis nacionais referentes à educação, LDB, PNE, Resoluções, Pareceres); 
c) Reformas educacionais;

d) Gestão da educação;

e) Políticas e Programas da Educação Básica;

f) Financiamento da educação;

g) Estado e educação (Stremel; Mainardes, 2015, p. 14).

A conclusão dos autores é de que esse campo da Política Educacional é muito amplo, e sugerem mais investigações, pois elas facilitarão a compreensão da disciplina e poderão oferecer melhorias a ela. Cristofoli (2015) atribui grande importância à Política Educacional na formação de professores. Segundo a autora, a disciplina possibilita o contato do aluno com a realidade escolar, e a compreensão da ação do Estado com suas responsabilidades e a legislação.

Um dos resultados obtidos por meio da pesquisa da autora revela que o conteúdo de maior dificuldade encontrado pelos alunos é o financiamento da educação brasileira, por ser um extenso e cansativo. Portanto, propõe metodologias diferentes para facilitar a compreensão dos alunos.

Mainardes, Stremel e Rosa (2017) ressaltam que o estudo relacionado com a disciplina de Política Educacional é relevante, pois possibilitou a criação, institucionalização e avanço de um campo acadêmico autônomo, e a busca em saber quais as metodologias utilizadas nessa disciplina nos cursos de Graduação e Pós-Graduação possibilitam maior envolvimento com os pesquisadores do campo da Política Educacional.

Os autores também sugerem novas pesquisas relacionadas à disciplina de Política Educacional, tendo em vista a sua importância e os desafios. Essas novas pesquisas podem ter como o foco

[...] aspectos históricos da disciplina Política Educacional nos cursos de formação de professores; designações utilizadas pelas Instituições; carga horária; análise de ementas, de planos de ensino (programas), de bibliografias; perfil dos docentes; opinião de alunos; análise de livros de natureza didática da disciplina; estudos comparativos da disciplina em diferentes países, etc. (Mainardes; Stremel; Rosa, 2017, pp. 299-300).

Em relação à metodologia utilizada na disciplina de Política Educacional, Pronko (2015, p. 253) revela que o uso do materialismo histórico está sendo abolido das salas de aula, "desprezando-se sua contribuição para a compreensão da dinâmica social numa perspectiva de transformação da realidade". Muitas vezes, o que se vê são alunos com pouco conhecimento sobre o materialismo histórico:

Os estudantes chegam a esses espaços curriculares com um conhecimento escasso e/ou caricaturado dos autores que fundamentam essa perspectiva teórico-metodológica e encontram dificuldades importantes na hora de apreender desde essa perspectiva, uma dinâmica social que se apresenta, hegemonicamente, de maneira bem distinta (Pronko, 2015, p. 253).

Para a autora, tendo em vista que a carga horária da disciplina nos cursos de Pedagogia é insuficiente, os alunos não compreendem as leituras e não desenvolvem bem os trabalhos finais da disciplina.

Outra pesquisa relacionada à disciplina de Política Educacional é da autora Mendes (2015), com o objetivo de compreender a importância da disciplina Educação Brasileira e Organização das Políticas Públicas (Ebopp) na formação dos professores, teve como foco respostas e comentários de alunos matriculados em cursos de Licenciatura. 
O interesse dos alunos por essa disciplina foi o principal motivo da pesquisa. Participaram da pesquisa 52 alunos que, em geral, responderam que se interessam pela disciplina, que gostam de debates sobre questões políticas e que poucas vezes participaram de algum durante a vida escolar. Eles atribuíram importância da disciplina na formação dos professores, destacando alguns argumentos, tais como: "para analisar as políticas educacionais; para a vida profissional e para aprender a ser professor; para aprender como o Estado funciona, conhecer as leis e fazer valer os direitos: para compreender o mundo, a realidade" (Mendes, 2015, p. 14).

Em relação aos aspectos negativos, os alunos concordaram que falta carga horária para a disciplina; e de positivo, destacaram a metodologia e o trabalho do professor.

Moreira e Iulianelli (2017) pesquisaram a disciplina de Política Educacional em Instituições de Ensino Superior do Rio de Janeiro e a formação docente. Moreira e Iulianelli (2017), partindo do pressuposto de que o ensino da disciplina política educacional pode proporcionar aos futuros educadores uma compreensão crítica das políticas, analisaram 10 ementas de seis Instituições de Ensino Superior (IES) do Rio de Janeiro e concluíram que o papel da disciplina é mais informativo do que formativo.

Rosa (2016) também pesquisou a disciplina nos cursos de Pedagogia e Licenciaturas na Universidade Estadual de Ponta Grossa (UEPG). Mais uma vez a disciplina é apresentada como de suma importância na formação dos professores, e o autor conclui que o vínculo do professor que leciona essa disciplina deve estar ligado com as pesquisas no campo da Política Educacional, a fim de melhorar o ensino e contribuir com as discussões em torno desse tema.

No âmbito internacional, Mancebo (2017) investigou o ensino de Política Educacional no Uruguai, e trouxe algumas considerações para compreender como ocorre esse ensino fora do Brasil. O objetivo da autora foi investigar como ocorre o treinamento dos professores para o ensino da Política Educacional, e a conclusão foi de que esse treinamento é escasso:

En Uruguay la actual oferta de formación en PE es escasa y se concentra, fundamentalmente, en postgrados públicos y privados, todos ellos radicados en Montevideo. Particularmente preocupante es el déficit de formación en PE en las carreras de Magisterio y Profesorado [...] (Mancebo, 2017, p. 12).

Giovine (2016) investigou sobre o ensino da Política Educacional nos programas de formação docente da Argentina, realizando um estudo histórico desde a década de 1980. A autora concluiu que as disciplinas que compõem a Ciência da Educação, principalmente as ciências políticas, diferenciam-se das demais ciências por não apresentarem um status disciplinar claro:

[...] aún se observa cierta debilidad teórica producto de su propia indefinición disciplinaria, al establecer relaciones no siempre claras entre las ciencias sociales y políticas, más específicamente entre las ciencias políticas, el derecho, la sociología, la historia y la pedagogía -para señalar las principales-, dando cuenta de lo que Cesar Tello (2015) caracteriza como un "campo congestionado y confuso" (p.127). (Giovine, 2016, p. 471).

Além disso, há outro obstáculo no ensino da Política Educacional, e o que se necessita é "una mayor explicitación de los abordajes teóricos y metodológicos, aún es necesaria una mayor explicitación de las vinculaciones ontológicas, epistemológicas y metodológicas que guían al análisis político de lo escolar y lo educativo" (Giovine, 2016, p. 472). 


\section{A organização da disciplina de Política Educacional}

O estado do Paraná possui, no total, sete universidades estaduais ${ }^{1}$ e três universidades federais ${ }^{2}$. Na tabela 1 apresentamos a carga horária e etapa em que a disciplina de Política Educacional é ofertada nas respectivas universidades.

Tabela 1 - Programa da disciplina de Política Educacional no curso de Pedagogia: Universidades estaduais do Paraná

\begin{tabular}{c|c|c} 
Instituição & Carga horária & Ano de oferta \\
\hline Instituição A & $102 \mathrm{~h} / \mathrm{a}$ & $2^{\circ}$ Ano \\
\hline Instituição B & $* 136 \mathrm{~h} / \mathrm{a} * * 68 \mathrm{~h} / \mathrm{a}$ & $* 3^{\circ}$ Ano \\
\hline Instituição C & & $* * 4^{\circ}$ Ano \\
\hline Instituição D & $102 \mathrm{~h} / \mathrm{a}$ & $1^{\circ}$ Ano \\
\hline Instituição E & $60 \mathrm{~h} / \mathrm{a}$ & $1^{\circ}$ Ano \\
\hline Instituição F & $60 \mathrm{~h} / \mathrm{a}$ & $1^{\circ}$ Ano \\
\hline Instituição G & $* 68 \mathrm{~h} / \mathrm{a} * * 34 \mathrm{~h} / \mathrm{a} * * * 34 \mathrm{~h} / \mathrm{a}$ & $* 1^{\circ}$ Ano; $* * 2^{\circ}$ Ano; $* * * 3^{\circ}$ Ano; \\
& $* * * * 68 \mathrm{~h} / \mathrm{a}$ & $* 4^{\circ}$ Ano \\
\hline
\end{tabular}

Fonte: Dados organizados pelas autoras com base nos sites das universidades.

Observação: Na instituição B há duas nomenclaturas da disciplina de Política Educacional: Política Educacional Brasileira I, representada por * e Política Educacional Brasileira II, com representação **. Na instituição F há quatro nomenclaturas relacionadas com a disciplina de Política Educacional: Políticas Públicas e Gestão Educacional: Identidade do Pedagogo nos processos escolares e não escolares, representada por *; Políticas, Gestão e Diversidade, cuja representação é por **; Políticas Públicas e Gestão da Educação Brasileira, com representação de ***; Políticas Públicas e Gestão Educacional: Docência e Diversidade Cultural, representada por ****. Na instituição $G$ há duas nomenclaturas relacionadas com a disciplina de Política Educacional: Políticas Públicas em Educação, com representação de * e Políticas, Educação e Diversidade, cuja representação é por **.

Das sete universidades estaduais do Paraná, seis ofertam a disciplina de Política Educacional no $1^{\circ}$ ou $2^{\circ}$ ano do curso.

Stremel e Mainardes (2015) constataram que, das oitenta e nove universidades que ofertam o curso de Pedagogia no Brasil, cinquenta apresentavam as grades curriculares e ementas em seus sites, e vinte delas apresentavam apenas a estrutura curricular.

Levamos isto em consideração na seleção das universidades a serem pesquisadas, e selecionamos três que apresentavam, em seus sites, a grade curricular do curso de Pedagogia e as ementas e programas da disciplina de Política Educacional, além da informação com os nomes e e-mails dos professores dessa disciplina.

\footnotetext{
${ }^{1}$ Universidade Estadual do Centro Oeste (UNICENTRO); Universidade Estadual de Maringá (UEM); Universidade Estadual de Londrina (UEL); Universidade do Oeste do Paraná (UNIOESTE); Universidade Estadual do Paraná (UNESPAR); Universidade Estadual do Norte do Paraná - UENP; Universidade Estadual de Ponta Grossa (UEPG).

2 Universidade Federal do Paraná (UFPR); Universidade Federal da Integração Latino-Americana (UNILA); Universidade Tecnológica Federal do Paraná (UTFPR).
} 
Os dados levantados pela pesquisa revelaram a organização da disciplina de Política Educacional no curso de Pedagogia de três Universidades Estaduais do Paraná, destacando a nomenclatura, carga horária e ano de oferta (Quadro 1).

Quadro 1 - A organização da disciplina de Política Educacional

\begin{tabular}{|l|l|l|l|}
\hline & \multicolumn{1}{|c|}{ Nomenclatura da disciplina } & \multicolumn{1}{|c|}{ Carga horária } & Ano de oferta \\
\hline Instituição A & $\begin{array}{l}\text { Política e Organização da Educação } \\
\text { Brasileira }\end{array}$ & 102 horas/aulas & $2^{\circ}$ Ano \\
\hline Instituição B & Política Educacional Brasileira I* e II** & $* 136$ horas/aulas **68 horas/aulas & $\begin{array}{l}* 3^{\circ} \text { Ano } \\
* * 4^{\circ} \text { Ano }\end{array}$ \\
\hline Instituição C & $\begin{array}{l}\text { Política Educacional - Ensino } \\
\text { Fundamental }\end{array}$ & 102 horas/aulas & $1^{\circ}$ Ano \\
\hline
\end{tabular}

Fonte: Dados organizados pelas autoras com base nos sites das universidades.

Observação: $\mathrm{Na}$ instituição B há duas nomenclaturas da disciplina de Política Educacional: Política Educacional Brasileira I, representada por *; e Política Educacional Brasileira II, com representação **.

Observamos a nomenclatura das disciplinas, e os termos mais usados são política e educação. No entanto, Stremel e Mainardes (2015) concluíram, em sua pesquisa, que há noventa e sete designações para a disciplina de Política Educacional, resultando, assim, em uma dispersão do campo.

Moreira e Iulianelli (2017), ao pesquisarem as ementas da disciplina de Política Educacional em Instituições de Ensino Superior, constataram que "a disciplina aparece tanto com a denominação 'política educacional', quanto 'políticas educacionais', o que denota certa confusão entre a delimitação do próprio campo e o tratamento de objeto" (Moreira \& Iulianelli, 2017, p. 7).

Em relação à carga horária, Instituição A e a Instituição $C$ possuem a mesma quantidade, 102 horas/aulas, e a Instituição B possui duas disciplinas envolvendo a política educacional no curso de Pedagogia, com 136 horas/aulas no $3^{\circ}$ ano do curso e 68 horas/aulas no $4^{\circ}$ ano. A oferta da disciplina de Política Educacional na Instituição A ocorre no $2^{\circ}$ ano do curso de Pedagogia, e no $1^{\circ}$ ano na Instituição C.

Outro dado analisado na presente pesquisa foram as ementas das disciplinas dos três IES (Instituições de Ensino Superior) do Paraná (Quadro 2).

Quadro 2 - Ementas da disciplina de Política Educacional

\begin{tabular}{|c|l|}
\hline & \multicolumn{1}{|c|}{ Ementas } \\
\hline Instituição A & $\begin{array}{l}\text { Estudo do sistema educacional brasileiro, de seus aspectos organizacionais, de suas políticas e } \\
\text { das variáveis intervenientes na gestão da Educação Básica. Análise teórico-prática da } \\
\text { legislação vigente, aplicada à organização dos Sistemas e das Instituições Escolares em seus } \\
\text { aspectos políticos, administrativos, pedagógicos e financeiros. }\end{array}$ \\
\hline Instituição B & $\begin{array}{l}\text { *Identificação dos nexos entre o modo de produção capitalista, o Estado e a instituição das } \\
\text { leis e reformas educacionais da Educação Escolar no Brasil a partir do Império, e os } \\
\text { desdobramentos político-pedagógicos. **Exame da formulação da política educacional } \\
\text { brasileira contemporânea - legislação, projetos e programas - como resultado das disputas } \\
\text { entre os projetos educacionais dos diferentes grupos sociais. }\end{array}$ \\
\hline Instituição C & \begin{tabular}{l} 
Investigação da organização e do funcionamento escolar. Análise da educação básica no \\
\hline
\end{tabular}
\end{tabular}


contexto da sociedade brasileira. Estudo dos fundamentos teóricos que norteiam a estrutura do sistema educacional brasileiro. Pressupostos e metas das Leis de Diretrizes e Bases da Educação Nacional. As políticas e a legislação na Educação Básica no País, Estado e no Município.

Fonte: Dados organizados pelas autoras com base nos sites das universidades.

Observação: *Política Educacional Brasileira I. **Política Educacional Brasileira II.

Em relação às ementas da disciplina, os itens mais comuns encontrados foram: Estudo do sistema educacional brasileiro, conceito de Estado e aplicação das leis da educação no sistema de ensino. Como afirmam Stremel e Mainardes (2015), não há termos identificados nas ementas em relação a aspectos metodológicos em pesquisa no campo da política, e isto se deve pela curta carga horária da disciplina.

Após a análise da organização da disciplina de Política Educacional, realizamos um levantamento de dados com os professores que ministram esta disciplina nas instituições pesquisadas, por meio de um questionário com seis perguntas abertas, via on-line. Para identificarmos esses professores, levantamos informações nos sites das instituições. professores:

No quadro 3 apresentamos as seis perguntas presentes no questionário direcionadas aos

Quadro 3-Questionário sobre a disciplina de Política Educacional

\begin{tabular}{|l|l|}
\hline $\mathbf{N}^{\mathbf{0}}$ & Perguntas \\
\hline 1 & Há quanto tempo é professor (a) da disciplina de Política Educacional? \\
\hline 2 & $\begin{array}{l}\text { Em relação ao ano/série em que a disciplina é ofertada, quais são os desafios dessa organização } \\
\text { curricular? }\end{array}$ \\
\hline 3 & Em sua opinião, os conteúdos da disciplina são de difícil entendimento? Explique. \\
\hline 5 & Qual sua maior dificuldade em ministrar a disciplina? \\
\hline 6 & Se fosse possível alterar o programa da disciplina, o que você alteraria? \\
\hline
\end{tabular}

Fonte: Dados organizados pelas autoras.

As respostas dos professores para a pergunta no 1 estão dispostas no quadro 4.

Quadro 4-Organização das respostas à $1^{a}$ pergunta do questionário

\begin{tabular}{|c|l|l|l|l|}
\hline \multirow{2}{*}{$\mathbf{N}^{\mathbf{2}}$} & \multicolumn{1}{|c|}{ Perguntas } & \multicolumn{2}{|c|}{ Respostas } \\
\cline { 3 - 5 } & \multicolumn{1}{|c|}{ Professor 1 } & Professor 2 & Professor 3 \\
\hline 1 & $\begin{array}{l}\text { Há quanto tempo é professor (a) da disciplina } \\
\text { de Política Educacional? }\end{array}$ & $\begin{array}{l}\text { 5 anos no curso de } \\
\text { Pedagogia e mais } \\
\text { de 10 anos em } \\
\text { outros cursos de } \\
\text { licenciatura. }\end{array}$ & 10 anos & 5 anos \\
\hline
\end{tabular}

Fonte: Dados organizados pelas autoras. 
$\mathrm{Na}$ segunda pergunta, sobre os desafios encontrados na organização curricular da disciplina, o professor 1 aponta os seguintes desafios:

Por ser uma disciplina que necessita de outros conhecimentos (tais como bistória da educação
brasileira, sociologia e filosofia), penso que a maior dificuldade é a falta de conbecimento dos
alunos sobre os conteúdos dessas disciplinas, pois para compreender a Política Educacional é
necessário o dominio minimo de outros conhecimentos (essas disciplinas são ofertadas também
no $2^{\circ}$ ano do curso) [...] Ainda, para tratar de todos os conteúdos previstos a carga horária é
insuficiente, não ocorrendo o aprofundamento necessário para análises profundas a respeito dos
conteúdos previstos.

O professor 2 afirma que a organização curricular da disciplina contribui para melhorar o aprofundamento dos conteúdos, e responde:

Aqui a disciplina é subdividida em duas fases, a primeira com carga horária de $136 \mathrm{~b} / \mathrm{a}$ contempla a fase do império até a abertura democrática, oferecida no terceiro ano do curso, momento em que o aluno já apresenta uma maturidade de leitura e interpretação, portanto, julgo pertinente. Quanto à segunda parte, oferecida no quarto e último ano do curso com carga horária de $68 \mathrm{~h} / \mathrm{a}$, engloba o período a partir dos anos 1990. Nesse caso, o conjunto de leituras acumulado pelos alunos no quarto ano, colabora com o desenvolvimento da disciplina.

O professor 3 pontuou alguns aspectos em relação à estrutura curricular da disciplina de Política Educacional em sua instituição. Em relação aos aspectos positivos, o professor respondeu: "o acadêmico tem a possibilidade de conhecer as politicas educacionais de modo geral, além de conceitos importantes para a compreensão do processo educativo". Em contrapartida, há "dificuldade na leitura dos textos, além de ausência de conbecimentos básicos sobre a bistória e política do nosso país".

Percebemos que, para os professores 1 e 3, em que a disciplina é ofertada respectivamente no $2^{\circ}$ e $1^{\circ}$ ano, há a necessidade de alterar essa estrutura curricular. Stremel e Mainardes (2015) revelam que, de cento e vinte e oito disciplinas de política educacional, trinta e oito são ofertadas no $1^{\circ}$ ano, e cinquenta no $2^{\circ}$ ano do curso de Pedagogia.

Mendes (2015, p. 4) afirma:

Frequentar a disciplina logo no início do curso pode ser positivo, por propiciar ao acadêmico o acesso ao estudo e ao debate sobre temas que auxiliarão na compreensão de um conjunto de circunstâncias que serão vivenciadas em situações de estágio. Entretanto, pode ser negativo, na medida em que o estudante não teve um contato mais sistematizado com as questões educacionais dentro do curso que forneça subsídios para um entendimento mais qualificado das implicações das políticas educacionais no cotidiano escolar.

Em relação à resposta da terceira pergunta, os três professores concordaram que os conteúdos necessitam de maior atenção dos alunos, pois tratam de assuntos complexos e que só podem ser compreendidos com a ajuda de outras disciplinas do curso, principalmente a de História.

$\mathrm{Na}$ quarta pergunta, o professor 1 e o professor 3 responderam o mesmo. Segundo eles, é muito conteúdo para pouco tempo, impedindo, assim, maior aprofundamento nos temas a serem discutidos e compreendidos. Para o professor 2, é a "constante transformação" do objeto de estudo que torna o ensino mais complexo; portanto, necessita de um "constante acompanbamento".

$\mathrm{Na}$ análise de Stremel e Mainardes (2015), o uso apenas de livros na disciplina de política educacional pode comprometer a aplicabilidade dos conteúdos, pois envolvem várias temáticas e 
tratam de aspectos legais, sendo dinâmicos e requerem certas atualizações que os livros não oferecem com a regularidade necessária.

Os professores responderam de forma semelhante à quinta pergunta: eles aumentariam a carga horária da disciplina, dividindo-a em duas etapas, ou seja, dois anos consecutivos, para que fossem trabalhados todos os conteúdos e que fossem totalmente compreendidos pelos alunos.

Por fim, a sexta e última pergunta estava relacionada à importância que os professores atribuíam à disciplina de política educacional no curso de Pedagogia. As respostas foram semelhantes, ao afirmarem que essa disciplina possibilita, aos futuros professores, a compreensão do sistema educacional, e lhes prepara para o futuro campo de trabalho.

Flach e Masson (2014) afirmam que a disciplina de Política Educacional, como eixo, é inquestionável, pois oferece, ao futuro professor, estudos e reflexões que serão vistos em seu campo de trabalho.

\section{Considerações finais}

Por meio desta pesquisa, concluímos que o campo da política educacional está em construção, e que necessita cada vez mais de estudos aprofundados sobre o tema (Stremel \& Mainardes, 2015). Além disto, percebemos a importância da disciplina de Política Educacional, destacando sua função em preparar o futuro professor para atuar na educação e compreender a legislação e os desafios presentes na área educacional.

Em relação aos dados levantados, descobrimos como a disciplina é apresentada em outras Instituições de Ensino Superior. Por meio desta troca de informações, mostramos que os conteúdos a serem trabalhados e a organização curricular são semelhantes, assim como a resposta dos professores, que veem como melhor a divisão da disciplina em duas etapas, a fim de conseguirem ministrar todo o conteúdo previsto.

Sugerimos que novas pesquisas em relação à disciplina de Política Educacional sejam realizadas. Esta, por exemplo, teve o foco nas informações dos professores, mas devem realizadas novas pesquisas ouvindo mais alunos acadêmicos que cursam essa disciplina, e um número maior de professores, visto que os resultados apresentados por meio das pesquisas aqui relatadas são semelhantes e nacionais.

O problema relacionado à insuficiente carga horária da disciplina afeta o ensino do professor e a aprendizagem dos alunos. Em uma época de reformulação dos cursos de Pedagogia e das Licenciaturas, é necessário que as universidades se manifestem em defesa de uma educação de qualidade. Com os resultados das pesquisas, as universidades estarão fazendo jus ao nome Ensino, Pesquisa e Extensão, aproximando, deste modo, a teoria da prática. Também os pesquisadores desse campo de estudo, dando cada vez mais destaque à Política Educacional.

Identificamos que a disciplina de Política Educacional tem suma importância na formação de professores e que, por este motivo e outros, necessita de mais atenção nos projetos pedagógicos dos cursos, para que seja desenvolvida da melhor maneira possível aos alunos.

\section{Referências}

Brasil. Decreto 19.851, de 11 de abril de 1931. Estatuto das Universidades Brasileiras. 
Brasil. Decreto-Lei n ${ }^{0} 1190$ de 04/04/1939. Organiza a Faculdade Nacional de Filosofia. 1939. Disponível em www.senado.gov.br. Último acesso em 11 de novembro de 2006.

Brasil. Parecer CFE n²52, de 11 de abril de 1969. Fixa a duração do currículo mínimo do curso de Pedagogia.

Costa, A. C., Muranaka, M. A. S., \& Borghi, R. F. (2016). A contribuição da disciplina PEB à formação de professores do ensino básico: estudo do caso das licenciaturas em uma universidade estadual. Anais do I Encontro Latino-americano de professores de politica educativa e II Seminário Internacional de questões de pesquisa em educaşão, 2015, São Paulo, SP, Brasil, 1, pp. 1-24.

Cristofoli, M. S. (2015). “O estudo da política educacional como componente curricular dos cursos de formação de professores nas universidades públicas”. Políticas Educativas, 8 (2), 1-15.

Flach, S. F., \& Masson, G. (2014). "A disciplina de política educacional em cursos de formação de professores”. Revista Pedagógica, 16 (33), 205-220.

Giovine, R. (2016). El oficio de enseñar política educativa: desplazamientos políticos y epistemológicos en los programas de formación docente universitaria en Argentina. Revista de Estudios Teóricos y Epistemológicos en Politica Educativa, 1 (2) 451-476.

Guimarães-Iosif, R., Limeira, L. C. \& Santos, A.V. (2018) O ensino de Política e Gestão Educacional nos cursos de licenciatura. Práxis Educativa, 13 (1), 1-22.

Júnior, M. S., \& Galvão, A. M. O. (2005). "História das disciplinas escolares e história da educação: algumas reflexões”. Educação e Pesquisa, 31 (3), 391-408.

Mainardes, J., \& Stremel, S. (2017). Aspectos da formação do pesquisador em Política Educacional na Pós-Graduação no Brasil. Anais do Congreso Latinoamericano y Caribeño de Ciencias Sociales, Salamanca, Espanha, 4.

Mainardes, J., Stremel, S., \& Rosa, G. L. R. (2017). "A pesquisa sobre a disciplina Política Educacional no Brasil: situação e perspectivas". Revista Brasileira de Política e Administração de Educação, 33 (2), 287-307.

Mancebo, M. E. (2017). La enseñanza de Política Educativa en Uruguay: ¿acumulación incipiente o rezago? Revista de Estudios Teóricos y Epistemológicos en Política Educativa, 2, 1-15.

Mendes, V. (2015). "O estudo da política educacional nos cursos de licenciatura de uma instituição federal de ensino superior". Anais do I Encontro Latino-americano de professores de política educativa e II Seminário Internacional de questões de pesquisa em educação, São Paulo, SP, Brasil, pp. 1-21.

Moreira, L. P., \& Iulianelli, J. A. S. (2017). "Formação docente e ensino de política educacional em instituições de educação superior do Rio de Janeiro". Ensaio: Avaliação e Políticas Públicas em Educação, Rio de Janeiro, 25 (97), 854-873.

Oliveira, D. A. Política educacional. Dicionário - Verbetes. Grupo de Estudos sobre Política Educacional e Trabalho Docente - Gestrado - UFMG, 2010. Recuperado de http://www.gestrado.net.br/?pg=dicionario-verbetes\&id $=420$

Pronko, M. A. (2015). Desafios teórico-metodológicos para o ensino de políticas educacionais na perspectiva do materialismo histórico. In: Anais do I Encontro Latino-americano de professores de política educativa e II Seminário Internacional de questões de pesquisa em educação, Guarulhos-SP. Anais... Guarulhos-SP: UNIFESP. p. 1-17. 
Pronko, M. A. (2016). "Desafios teórico-metodológicos para o ensino de políticas educacionais na perspectiva do materialismo histórico". Revista de Estudios Teóricos y Epistemológicos en Política Educativa, 1 (2), 1-17.

Rosa, G. L. R. (2016). A disciplina Política Educacional no curso de Pedagogia e Licenciaturas da Universidade Estadual de Ponta Grossa. Trabalho de Conclusão de Curso (Pedagogia), Universidade Estadual de Ponta Grossa, Ponta Grossa, PR, Brasil.

Sheen, M. R. C. C. (2007). "A política educacional como momento de hegemonia: notas metodológicas a partir das contribuições de Antonio Gramsci”. Revista HISTEDBR On-line, 25, 312.

Stremel, S. (2016). A constituição do campo acadêmico da política educacional no Brasil. 2016. 315 f. Tese de Doutorado em Educação, Universidade Estadual de Ponta Grossa, Ponta Grossa, PR, Brasil.

Stremel, S. (2017). "Aspectos teórico-metodológicos para a análise da constituição do campo acadêmico da política educacional no Brasil". Revista de Estudios teóricos y Epistemológicos en Política Educativa, 2, 1-4.

Stremel, S., \& Mainardes, J. (2015). “A disciplina Política Educacional em cursos de Pedagogia no Brasil: primeiras aproximações”. Jornal de Políticas Educacionais, 9 (17-18), 137-155.

Stremel, S., \& Mainardes, J. (2016). A emergência do campo acadêmico da política educacional em diferentes países. Tópicos Educacionais, 22 (1), 62-85.

UEL. Ementa curso de Pedagogia UEL. Recuperado de http://www.uel.br/prograd/catalogocursos/catalogo_2016/ementas/pedagogia_noturno.pdf

UEL. Matriz curricular curso de Pedagogia UEL. Recuperado de http://www.uel.br/prograd/catalogo-

cursos/catalogo_2016/organizacao_curricular/pedagogia_noturno.pdf

UEM. Ementa e Matriz curricular curso de Pedagogia UEM. Recuperado de http://sites.uem.br/pen/deg/apoio-aos-colegiados-aco/documentos/cursos-

$1 /$ cursos/pedagogia-matutino-noturno

UENP. Universidade Estadual do Norte do Paraná. Recuperado de http://www.uenp.edu.br/

UEPG. Ementa e Matriz curricular curso de Pedagogia UEPG. Recuperado de http://www.uepg.br/catalogo/cursos/2016/pedagogo.pdf

UNESPAR. Ementa e Matriz, curricular curso de Pedagogia UNESPAR/ Campus Apucarana. Recuperado de http://www.fecea.br/userfiles/MATRIZ\%20CURRICULAR $\% 20 \mathrm{DO} \% 20 \mathrm{CURO} \% 20 \mathrm{DE} \% 20 \mathrm{P}$ EDAGOGIA.pdf

UNICENTRO. Ementa curso de Pedagogia UNICENTRO/Campus Irati. Recuperado de http://sguweb.unicentro.br/pdplanoensinos/visualizar/4e2a8866-014f-f013-fcb3-

e9393e716197/id2:0918\%7CI/url_return:\%7Cpdplanoensinos\%7Cpesquisa\%7C\%7C\%7CPddis ciplina1.cds_disciplina:Pol\%CC3\%ADtica

UNICENTRO. Matriz Curricular curso de Pedagogia UNICENTRO/Campus Irati. Recuperado de http://www2.unicentro.br/proen/ files/2016/12/Pedagogia-I.pdf?x34126 
UNIOESTE. Ementa e Matriq curricular curso de Pedagogia UNIOESTE. Recuperado de http://www5.unioeste.br/portalunioeste/cascavel/graduacao?campi=0\&curso=CSC0047.

Recebido: 20/09/2017

Versão revisada recebida: $18 / 10 / 2017$

Aceito: $24 / 10 / 2017$

Publicado online: $28 / 11 / 2017$

\section{Gislaine Macedo Marçal Perão}

Acadêmica do Curso de Licenciatura Pedagogia da Universidade Estadual do Centro Oeste (Campus Prudentópolis).

\section{Michelle Fernandes Lima}

Doutora em Educação pela UFPR (Brasil). Professora da Universidade Estadual do Centro-Oeste (Unicentro). 